\title{
El desarrollo y la nueva economía popular
}

\author{
Aquiles Montoya
}

\section{Introducción.}

Hasla hace algunos anos para la izquierda consecuente, esto es para la izquierda revolucionaria, el sub-desarrollo se presentaba -al menos teóricamente- como un problema de fácil solución. Así se veía que éste se lograria mediante el cambio del sistema, del modo de producción, lo cual exigía de la toma del poder y luego vendrían los cambios estructurales necesarios para sentar las bases del desarrollo. Tal planteamiento provenia de la lesis de que el capilalismo genera por si mismo pobreza y marginación social para amplios seclores de la población. Cabe a su vez agregar que el desarrollo no se concebía como un simple crecimiento económico sino como un desarrollo integral, esto es, en los diversos ámbitos de la aclividad humana.

En la actualidad la toma del poder se sigue considerando como algo posible, aunque hayan cambiado los medios para lograrlo, lo que si ya no se presenta como una meta -0 en todo caso lo que ya no se ve como factible en el corto o mediano plazo- es el cambio en el sistema o si preliere en el modo de producción y si ésle era el fundamento para la solución de los problemas del subdesarrollo o bien para alcanzar el desarrollo, pareciera, pues, que al menos teóricamente para la izquierda, se presenta un problema que exige de solución. Y no se crea que me esloy refiriendo únicamente a la izquierda salvadorena, sino en general a la izquierda marxisla, la cual tal parece que se encuentra como alurdida ante el derrumbe del socialismo histórico, del socialismo leninistaslaliniano. Alguna izquierda sigue hablando del socialismo pero lo hace sin convicción, en lanto lo vincula a una pretendida revolución democráti- 
ca, lo cual no deja de recordar aquella vieja tesis de la revolución democrático-burguesa, muy del gusto de los partidos comunistas tradicionales.

La problemálica actual quizás se pueda formular en los siguientes términos: ¿Cómo "llevar" desarrollo a los pobres y marginados de la sociedad sin transiormar el sistema? ¿Será esto posible? ¿Acaso se ha renunciado a la tesis anterior de que el sistema capilalista genera subdesarrollo, pobreza y marginación social para amplios sectores del campo y de la ciudad? ¿O acaso se ha terminado por aceptar que el desarrollo provendrá como consecuencia del crecimiento económico del seclor capitalista de la economía, cuyos "benelicios" rebalsarán hasta alcanzar a los pobres y marginados?

En mi opinión cualquier estralegia de desarrollo de la izquierda pasa por darle respuesla a lales interroganles. De algo de eso quiero hablar, pero no se crea que vengo con prelensiones de iluminado y poseo las respuestas absolutas para tales interrogantes; sin embargo, reconociendo la división social del trabajo como un hecho y un derecho no me voy a ocupar de la tolalidad de la realidad económico y social, sino tan sólo de una parte de la misma, porque ocurre que creo haber enconlrado entre las mayorias populares, en el trabajo que realiza algún seclor de esas mayorías populares, la solución a sus problemas de pobreza y marginación social, esto es su propio desarrollo, a eso le he denominado Nueva Economia Popular.

Pero, ¿qué entiendo por NEP? Por Nueva Economia Popular entendemos: una estrategia alternativa de y para las mayorias populares en los ámbitos económico, social, político y cullural, fundamenlada en su propio esfuerzo organizativo y productivo, que tiene por finalidad resolver los problemas de pobreza y marginación social de las mayorías populares del campo y de la ciudad, así como contribuir a la eliminación de las causas generantes de los mismos.

En consecuencia, si bien nos parece como posible que los seclores pobres y marginados avancen en la línea de su propio desarrollo, creemos que no se Irata de "llevarles" desarrollo, sino polenciar sus propios estuerzos organizativos y produclivos, en lal sentido se requiere de una labor de acompanamiento, de apoyo, de ayuda en los dilerentes ámbitos de su actividad. Y lodo ello sin necesidad de buscar primero un cambio en el sislema capitalista, pero cuidando de que todo ese esfuerzo no beneticie al sistema capitalista, ni que este sector popular de la economia sea absorbido por el sistema. No se trata pues de facilitarle el funcionamiento al sistema imperante, sino de ir generando desde la base misma algo alternativo.

Se habrá notado que no me esloy refiriendo a la sociedad civil, cate- 
goria que ha logrado aclualizarse nuevamenle,que eslá de moda,pues; sin embargo, a mi parece que es un "recipiente" que da cabida de manera indiferenciada a una excesiva realidad, borrando las diferencias entre las clases sociales, entre las capas sociales, etc. las cuales tienen su fundamento en las formas de propiedad y en las relaciones económicas y sociales que tenemos los diferentes inlegrantes de esa sociedad civil, es por ello, que prefiero referirme a una parte de esa realidad a la que denominamos mayorias populares y lales son, dicho rápidamente, todos aquellos sectores opuestos a las minorias privilegiadas y dentro de aquellas, son objeto y sujeto de nuestro estudio aquella Iracción de las mayorias populares no vinculadas por relaciones salariales al sector público y al sector capilalista de manera permanente, me parece que esos son efectivamente los más pobre y marginados. En consecuencia, lo que denominamos NEP es una estrategia allernativa de desarrollo de y para ellos.En resumen, pues, la respuesta al cómo "llevar" desarrollo a los pobres y marginados sin transiormar el sistema, se encuentra en la NEP. Desarrollaremos algunos de sus elementos posteriormente. Habiendo señalado lo anterior pasaré a ocuparme de la segunda interrogante y mi respuesla es afirmativa. Estoy convencido de que esa tracción de la sociedad civil puede lograr su propio desarrollo a través de la NEP y lo estoy, porque efectivamente ello está ocurriendo aunque lal utopia en marcha aún no tenga la importancia cuanlilativa que puede y liegará a tener. Esta realidad lluyente a la que yo denomino NEP, es posible observarla en diferentes comunidades vinculadas al FMLN, a algunas confesiones religiosas e incluso en otros esluerzos, al margen de los anteriores, aunque no siempre tengan claridad de lo que están realizando.Pero eso es lo menos imporlantes: "no lo saben pero lo hacen".

En cuanlo a la lercera interrogante: de que el sistema genera pobreza y marginación, es claro que así lo creemos, o sea pues que en ningún momento renunciamos a la tesis de que la pobreza y marginación social es consecuencia del sistema mismo, y por lal razón es que consideramos, precisamenle, que la NEP tendrá que llegar en su desarrollo, aunque no se lo proponga de manera consciente en la actualidad, a chocar con los estrechos marcos del sistema capilalista y al hacerio, de haber logrado la suficiente fuerza y desarrollo, se presentará una nueva coyunlura revolucionara que pudiera dar al traste con el sistema capitalisla a cuyo interior la NEP se ha venido desarrollando, aunque no como parte del mismo, sino como una nueva realidad que coexiste en y con el sislema pero que no se contunde con el mismo. (Esta es una vieja tesis marxista aunque reinterpretada a la luz de nuestra realidad y la experiencia histórica. Los sujelos del proyecto histórico no son los proletarios, sino las mayorias populares y el cambio de sistema no se ve a partir de 
un desarrollo de las fuerzas productivas, sino que a partir de su insuliciente desarrollo.) El capilalismo genera desarrollo para una pequefía fracción de la sociedad, pero su pretendido rebalse nunca alcanza a llegar a las mayorias populares, además de que ese limitado bienestar eslá fundamentado en la explolación de los asalariados y en la expoliación de los no asalariados. Todo ello constiluye una razón necesaria y suficiente para propugnar por la búsqueda de una nueva forma de organización social, pero ocurre adicionalmente que el estilo de desarrollo impulsado por el capitalismo - y de alguna manera por el socialismo leninista-staliniano- eslá conduciendo al suicidio colectivo de la humanidad y en su mortal carrera arrollarán con loda forma de vida en el planeta y ello hace necesario el pensar no sólo en un nuevo sistema económico, sino también en un nuevo estilo de desarrollo.

En consecuencia es necesario mantener de manera firme nuestro ideal de sustituir el sistema capitalisla y lo novedoso de la NEP en esle aspecto radica en que va gestándose en las entrañas del viejo sistema. (La cual lambién es otra vieja tesis marxista aunque no en el sentido en que la formuló Marx, porque él no conoció del subdesarrollo de cerca del $80 \%$ de la humanidad). La NEP, es pues, a nuestro juicio la allernativa que posee una parte de la sociedad civil para alcanzar su desarrollo, - en el límite podrá absorber al proletariado tradicional- con la ventaja de que ese desarrollo se va logrando día con día y no se está esperando la toma del poder para a partir de allí intentar la transtormación del sistema. Con ello no se pretende despreciar la toma del poder, pero no se trata de lograr un conlrol absoluto del poder como paso previo, cualquier cuola de poder que se alcance está bien, siempre y cuando se lenga claro que deberá utilizarse para potenciar el desarrollo de la NEP.

Ahora bien para que la NEP pueda desplegarse a plenitud se requiere de una serie de condiciones y que logre o conserve cierla identidad y cierta racionalidad propias y a su vez que se den una serie de premisas.

Entre las condiciones es importante destacar el papel que corresponde a las ONG vinculadas con los sectores populares, asi tendriamos en primer lugar, que descarten de una vez y para siempre la promoción humana asistencialista; en segundo lugar que realicen una promoción educativa que vaya desde la educación formal hasla la ideológica, pasando por la formación técnica en el más amplio sentido del término; en tercer lugar que continúen canalizando recursos financieros desde los paises ricos hacia los pobres, ello es parte de la solidaridad humana; en cuarto lugar, que no pretendan convertirse en sujetos de la NEP, sino tan sólo en acompanantes, en ayudantes, en lacilitadores o sea que busquen impulsar una promoción humana participativa y en quinto lugar, que 
avancen hacia la promoción humana Iransformacional, porque sólo transiormando el sislema se pueden eliminar las causas generantes de la pobreza y la marginación social. ${ }^{3}$

Procederemos ahora a ocuparnos de la racionalidad e idenlidad propias de la NEP, asi como de sus premisas, iniciando con éslas últimas. ${ }^{4}$

\section{Las Premlsas de la NEP.}

"a) La generación de un excedente neto por parte de cualquier unidad económica. La razón es simple y obvia: la generación del excedenle neto posibilita la reproducción en escala ampliada y al hacerlo se va tornando posible cumplir los objelivos primarios de la NEP, cuales son: generación de nuevos puestos de trabajo, incremenlo en los niveles de ingresos y salislacción de las necesidades sociales de sus miembros.

Esto es de suma importancia ya que de no ser asi no tendría ninguna viabilidad fulura y tampoco razón de ser. Una estrategia económicosocial que sea incapaz de generar excedentes netos no es una estrategia económica.

Ello no implica que en su primera fase los nuevos proyeclos pudieran cumplir una función de mera sobrevivencia para las mayorías populares: incluso las empresas capilalistas en un primer momento pueden operar con pérdidas. La cuestión es que ese momento debe de ser tan solo una fase transiloria y cuanlo más corla posible, mejor.

Adicionalmenle es preciso sefialar que cuando el excedenle se presenle, su mayor proporción, si no su lotalidad, debe de destinarse a la re-inversión más que a su consumo, ya que ello posibilitará un ritmo de crecimienlo más rápido de las unidades económicas, lo cual traerá mayores ventajas a futuro para los integrantes de la comunidad.

b) La eficiencia en la gestión económica, la cual se presenta como un presupuesto para la generación del excedente neto. En el ámbito de la producción ello implicaría la generación de una mayor cantidad de valores de uso con los menores cosios posibles, esto es, una optimización de los recursos. Lo cual, cierlamente, no significa como en la producción capilalisla comprimir las remuneraciones a los trabajadores. La eficiencia en la actividad económica eslá vinculada al empleo de las lécnicas apropiadas conforme a la disponibilidad de recursos humanos y materiales; a la capacitación formal y tecno-adminislralivo, asi como a la oblención y manejo de recursos financieros y de las necesarias técnicas de comercialización. Cuidando sobremanera los conlroles de calidad de los productos y servicios,porque como diria Marx: las mercancias para realizarse como valores de uso deben primero realizarse como valores y para 
realizarse como valores deben acredilarse como valores de uso.

De manera general es preciso sefialar que en cuanto a la eficiencia económica se refiere, las unidades económicas de la NEP deben de operar como auténticas empresas aunque lo sean de carácter autogeslionario. El ser una empresa autogestionaria no puede, ni debe ser excusa para la ineliciencia o para el despilfarro de los ingresos; el lujo y el despilfarro son los gastos de representación del capital pero la NEP no tiene porqué emular tales prácticas de un sistema que le es ajeno.

c) La integración inter e intrasectorial se presenta como otra premisa básica para la NEP, lo cual ciertamenle no implica pretensiones de autarquia, pero es obvio que cuanlo más integradas se encuentren las dilerentes unidades de la NEP, mayor posibilidad lendrá ésta de lograr un crecimiento aulogenerado y dinámico.

La razón de ello radica en que a medida que se tuesen incremenlando las unidades económicas y fuesen experimentando a su vez un mayor desarrollo en si mismas, esto conduciria a incrementar los ingresos disponibles de sus miembros, lo cual eslaria generando un incremento en la demanda de bienes y/o servicios de consumo, lo cual provocaría en las unidades económicas una mayor demanda de medios de producción, lo cual se traduciria en un incremento de la producción de tales productos y asi sucesivamente.

Como se podrá apreciar en lo anles sen̂alado el dinamismo de la NEP radica en si misma, lo cual asegura un crecimienlo sostenido y sostenible en el liempo. Ello resulla mucho más comprensible si consideramos que la NEP presupone implicilamente la imposibilidad de la concentración de los ingresos en manos de los sujetos individuales. Ahora bien, sefhalábamos que la NEP no prelende la aularquía económica, lo cual implica que así como no buscará autoabastecerse tampoco estará cerrada a la realización de sus mercancias en el sector capilalista, pero ello se presenla como un medio para lograr un mejor funcionamiento y no como un fin en si mismo, ya que de lo contrario se estaría Irasladando el molor de su crecimiento fuera de si misma y estaría perdiendo su dinámica propia.

Sin embargo, lal integración no sería posible conseguirla dejando la asignación de recursos al mercado, por lo que, al menos en su primera fase de desarrollo, la NEP presenta la necesidad de contar con algunas instancias de coordinación y planilicación, siendo así, pues, que olras premisas básicas de la NEP son la coordinación y la planificación.

d) La coordinación debe darse entre lodas aquellas organizaciones que de una u otra manera buscan promover proyectos económicos entre los seclores populares, ya que ello evilaría el desperdicio de esluerzos y 
de recursos y a su vez posibilitaria el ir generando los diversos eslabones necesarios para la integración de las diferentes unidades económicas que integran la NEP.Así como entre todas aquellas empresas existente bajo la forma de economia popular que presentan grandes potencialidades para su transformación en elemenlos inlegrantes de la NEP.

Para comprender la imporlancia y necesidad de la coordinación basta con pensar en la cantidad de instiluciones gubernamentales y ONGs involucradas con los sectores populares que de no realizar un esluerzo coordinado podrian incluso, llegar a entorpecer sus propios trabajos, además de imposibilitar cualquier esluerzo planificador.

e) La planilicación, por otra parte, se presenta como el elemento complementario de la coordinación en tanto no sólo posibililaria la integración de la NEP, sino que a su vez concretizaria los esluerzos de coordinación. También la planificación presenta la ventaja de posibilitar un crecimiento armónico y proporcionado de las dilerentes ramas y sectores de la NEP, evilando los costos de efectuar correcciones a posteriori como los que posibilita realizar el mercado.

La planificación, tanto al interior de las unidades económicas como de la NEP como un lodo, es un instrumento económico que es preciso revalorar a fin de obtener con el mismo la máxima eficiencia social posible. Ciertamente no se presenta como un sustituto para el mercado, sino como un corrector o regulador del mismo, en tal sentido, la planificación no es incompatible con el mercado sino complementaria. La planilicación vendría a ser como el lazarillo ante la ceguera del mercado, ciertamenle no posibilita ver pero si evila el caer en cualquier agujero.

1) Finalmente nos parece que otra premisa básica de la NEP es la organización, lanto a nivel de las unidades económicas, de las comunidades, de las actividades corno de los sectores. Tan imporlanle y necesaria es la organización a nivel de una unidad productiva -la cooperativa, por ejemplo- como a nivel de las dilerenles cooperativas del sector agropecuario o a nivel nacional. Tal organización es de suma importancia para hacer posible las anleriores premisas de la NEP, asi como para transtormar la debilidad individual que presentan las unidades económicas en lortaleza. Ciertamenle, un pequeño productor de granos básicos, individualmente considerado se caracteriza por su debilidad, por su incapacidad para influir en las decisiones económicas que a él le alañen, sin embargo, si existiera una Asociación Nacional de Productores de Granos Básicos, tendria la fuerza económica y política necesaria no sólo para vetar la implementación de cualquier medida económica que le fuera desfavorable, sino que para exigir la implementación de aquellas acciones que les favorecieran a sus asociados. 
Por otra parte sólo a través de la organización es posible ir avanzando hacia la novedad en las lormas económicas, acordes con las necesidades de los diferentes agentes económicos. La organización al polenciar al individuo, crea las bases para asimilar las ventajas de las formas asociativas en maleria económica, en lanto que la fortaleza del individuo no proviene de su individualidad sino de su unidad, con lo cual el sujelo coleclivo va desplazando al sujelo individual y el nosotros va reemplazando al yo. No se niega al individuo pero si se cuestiona al individualismo, por su carácter dispersor y debilitante.

En síntesis lenemos que las premisas básicas de la NEP son: la generación de un excedenle nelo, la eficiencia en la geslión económica, la integración inter e intrasectorial, la coordinación, la planilicación y la organización." (Monloya, 1992:262-265)

\section{La Idenlidad Propia de la NEP.}

Si bien los sujetos empíricos que conforman esa nueva realidad denominada NEP presentan una elevada helerogeneidad, la cual se manifiesta en sus dislintos origenes, niveles de desarrollo, en sus aclividades, en sus ámbilos geográficos, en sus formas de organización y de propiedad, elc. no es menos cierlo que presentan una serie de caracieristicas comunes que conforman su identidad, eslo es, aquello que les es propio y que les especifica, que les hace ser esa realidad fluyente denominada NEP. Ello es asi, no obslante que algunas de las características que sefialaremos puedan encontrarse presentes en otras realidades diferentes a la NEP, pero que en ésta es su globalidad la que le idenlifica.

Para efectuar esta caracterización que identifica a la NEP y que le diferencia del Sector Informal Urbano o de los pequefios empresarios agropecuarios, usaremos algunas lormulaciones anteriores nuestras y otros planteamientos de Razeto que se ajustan a nuestra propia realidad, cuando existe coincidencia hemos preferido dejarlo como cita del autor chileno, veamos:

a) Son iniciativas que se dan en los sectores populares (lo cual puede expresarse de varias maneras: entre los pobres del campo y la ciudad, en las clases subordinadas, en los grupos de menores ingresos, etc)

b) No son iniciativas puramente individuales sino asociativas que involucran a grupos de personas y de lamilias..

c) Son iniciativas organizativas, que dan lugar a organizaciones, lo cual supone que explícila o informalmente el grupo se plantea objetivos, se da una estructura y normalmente una direcliva... 
d) Son iniciativas creadas para enfrentar un conjunto de carencias y necesidades concretas, de aquellas que habitualmente se considera como necesidades económicas: alimentación, vivienda, salud, educación, trabajo, ingresos...

e) En eslas organizaciones se busca enfrentar estos problemas y necesidades mediante el propio esfuerzo y con la utilización de los recursos que para tal propósito se logra juntar.

e) Son iniciativas que implican relaciones y valores solidarios...

1) Son organizaciones que quieren ser participativas, democráticas, autogestionarias y autonomas,...

g) Son iniciativas que no se limitan a un solo tipo de actividades, sino que tienden a ser integrales... combinan actividades económicas, sociales, educativas, de desarrollo personal y grupal, de solidaridad, y a menudo también de acción política y pasloral...

h) Son iniciativas en las que se pretende ser distintos y alternativos respecto al sistema imperanle...

i) Son experiencias que surgiendo de los sectores populares para hacer frente a sus necesidades, habitualmente son apoyadas por actividades de promoción, capacitación, asesoria, donación de recursos materiales, etc.

Los diez elementos sefialados parecen formar parte de una racionalidad especial, de una lógica interna sustentada en un tipo de comportamientos o de prácticas sociales distinto de otros con los que se podrian comparar.(Razelo, 1990:49-52)

Adicionalmente, nosotros considerábamos que la propiedad se fundamenta en el propio trabajo y no en un lítulo de propiedad, con lo cual queda superado el problema de la explotación y se sientan las bases para buscar disminuir la expoliación que sufre la economia popular en sus relaciones con el seclor capitalista de la economia. También planteábamos que al generar el Irabajo propiedad sobre to producido se elimina materialmente el carácter alienado y alienante del trabajo propio de la producción capilalista, en consecuencia, la NEP, de suyo, presenta un carácler liberador. Por otra parle, sus integrantes se caracterizan por la creatividad, la mistica y la disciplina, elementos heredados de las condiciones de guerra en las cuales se fueron formando, ya sea que hubiesen vivido en el pais o en campos de refugiados en el exterior.

Como se puede apreciar en lo anteriormente sefialado nos encontramos ante un tenómeno nuevo, que no puede ser confundido con el sector informal ubano, con el cooperalivismo como fenómeno aislado, 
con alguna modalidad de socialismo conocida, mucho menos con la economía capitalista. Nos encontramos, pues, ante una realidad inédita que posee su identidad propia y que si bien puede presentar, teóricamente hablando, elemenlos comunes con el socialismo ulópico o el socialismo histórico, se aproxima más a la civilización del trabajo de la cual nos hablaba Ellacuría."

\section{La Racionalidad Propia de la NEP.}

"Imbuidos como estamos de la racionalidad capitalisla pareciera que no es posible que exista otro tipo de racionalidad. A cualquier economista le resulla una total herejía el solo hecho de suponer que pueda existir otra lógica diferente a la denominada eficiencia, medida en términos del beneficio capitalista, sin percatarse que tal racionalidad tiene un carácier histórico como el capitalismo mismo y que no siempre ha sido asi y que no tiene tampoco porque ser siempre de esa manera. Asi tenemos que, Godelier, por ejemplo, alirma: "No existe... racionalidad económica en si, definitiva y absoluta." (Godelier, 1976:305) Y es que "la noción de racionalidad económica se organiza en torno a dos polos de significado. Por economia racional se plantea una economía eficiente y una economía justa. La eficiencia remite a las estrucluras técnicas de la producción...y la justicia remite a las relaciones de los hombres entre si en el acceso a los recursos y al producto social." (Godelier, 1976:300) Y más delante acota, "Empero, la maximización de la producción no tiene sentido si no se refiere a la jerarquia de las necesidades y de los valores que se imponen a los individuos en el seno de una sociedad determinada y tienen su fundamento en la naturaleza de las estrucluras de esta sociedad" (Godelier,303:1976)

En consecuencia, para caplar la racionalidad que le es propia a la NEP es preciso lener en mente quiénes son sus sujetos, cuál es su ulopia, cuál es su identidad, cuáles son sus formas de propiedad y cuáles sus relaciones económicas, sólo entonces adquiere sentido el senalar, -como to hace Razelo- que los elementos de tal peculiar racionalidad son:

"Un primer elemento de esta racionalidad consiste en que el objetivo de estas organizaciones es entrentar unidamente un conjunto de necesidades humanas, individuales y sociales: necesidades de subsislencia fisiológica, de convivencia y relación con los demás, de capacitación y desarrollo cultural, de crecimiento personal y de identidad social, de autonomia e integración crítica a la sociedad. En este sentido se trata de organizaciones económicas pero no economicislas.

La participación de las personas en ellas implica no solamente Irabajar, 
producir, vender y comprar, sino todo un modo de vida, una práctica social y grupal compleja que liende a ser inlegral: más que de "estrategias de subsistencia" habria que hablar de estrategias de vida.

Un segundo elemenlo de esla racionalidad económica consisle en un vínculo estrecho que en ellas se establece entre producción, distribución y consumo...

El tercer elemento, derivado de los anteriores, se refiere al concepto de eficiencia que es propio de estas unidades económicas. En ellas, la relación entre los objetivos y los medios, y entre los benelicios y los costos, individuos un cálculo esIriclamente cuantitativo. Objelivos y medios se encuentran altamente entrelazados; asi, el cumplimienlo de determinados objelivos (por ejemplo la satislacción de delerminadas necesidades básicas) puede ser un medio para la salisfacción de necesidades relacionales y de convivencia, y a la inversa. El uso del tiempo puede presentarse a la vez como un cosio y como el logro de ciertos objelivos. De este modo, no siempre es posible medir la eficiencia cuantitativamenle, porque los benelicios y los costos pueden no tener expresión monelaria,ni son completamente separables.

Las unidades económicas populares ofrecen a sus integrantes un conjunto de beneficios y satisfacciones extraeconómicas que se suman a la cuenta o apreciación global que cada miembro realiza. Cuando se mide el produclo generado por estas organizaciones, se ha de considerar no sólo la producción lísica sino también un conjunto de servicios que, si no hubieran sido generados en la misma organización, las personas habrian tenido que adquirir en el mercado.

También por el lado de los coslos, la operación implica un conjunlo de ahorros importantes: la gestión colectiva basada en trabajo adicional, la ausencia de cosios de información y comunicación, el autocontrol del trabajo, la gratuidad de numerosas prestaciones, el empleo de liempos parciales y discontinuos o de fuerza de trabajo secundaria que no tiene ocupación en olro lipo de empresas, el aporte de la creatividad social, el uso de medios de trabajo de bajo coslo, elc. constituyen un conjunto de aspectos que redundan en el hecho de que las unidades económicas solidarias operen con menores cosios de factores." (Razelo, 1990:78-80).

En cuanto al segundo elemento sefialado por Razeto, quisiéramos anadir que exisle además de la vinculación estrecha entre la producción, la distribución, el cambio y el consumo, una determinación última por la producción enlendida como totalidad. Asi por ejemplo, si la producción es comunitaria, la distribución y el consumo también lo son, $\theta$ incluso, ni se requiere de intercambio. Esto como se comprenderá hace referencia 
a un modelo puro, a nivel de realidad empirica las cosas son mucho más complejas, lo cual no niega las delerminaciones últimas sino que las matiza. En el capitalismo como sistema, la producción capitalista determina formas de distribución, de circulación y de consumo correspondientes. Al exislir una producción lundamentada en la propiedad privada capilalista, la distribución se realiza en base a la propiedad que cada quien posea. El capitalista participa de la misma en tanlo que propielario del capital y el obrero en base a la propiedad de su fuerza de trabajo. La circulación de lo producido ocurre bajo la modalidad de circulación mercantil capitalista. Y el consumo, no es por casualidad que se transforme en consumismo, sino porque la dinámica de la producción capitalista así lo exige. En la NEP si tenemos formas de propiedad no capilalistas, ni relaciones económicas de tal naturaleza es claro que le corresponden formas de producción diferentes, así como relaciones de distribución, de intercambio y de consumo dilerenles. En dos palabras, si se tienen estructuras y valores diferentes es claro que existirá una racionalidad económica diferente, que haga posible la eficiencia sin menoscabo de la justicia. De alli que las opciones lecnológicas no estarán orientadas por un eficienticismo o por la eficiencia en si misma, sino mediadas por la justicia social.

Sólo porque sabemos que Razelo teoriza a partir de la realidad chilena, no afirmamos que se está refiriendo a la experiencia nuestra, pero esa es una de las muchas ventajas que posee el hacer leoria, al abstraerse de los caracleres secundarios se capla la realidad esencial y ésta si puede expresar o explicar otra realidad similar.Hay un punto en lodo esio de suma imporlancia y que deseamos reiterar, tal racionalidad de la NEP, obviamente, no está presente en todas las experiencias empíricas, pero es parte también de su ulopia en marcha, es otro de sus elementos de gran potencialidad que es preciso no descuidar, sobre todo en la actualidad cuando las comunidades han entrado en conlacto directo con el seclor capilalisla de la economía y con las visiones propias de los lécnicos del sistema que no reconocen la posibilidad siquiera de otra racionalidad que no sea la capitalisla.

Adicionalmente, deseamos destacar que la racionalidad de la NEP sólo puede ser alcanzada a cabalidad en la medida que las diferentes unidades económicas integrantes de la misma, logren su articulación intra e intersectorial, porque entonces to que pudiera presentarse como "pérdida", "desperdicio" o "derroche" en una delerminada unidad económica estaría beneficiando a otra u olras unidades económicas de la NEP. con lo cual la totalidad tendria un resultado positivo." 
1. Ponencia presentada en el Taller "Democracia, Justicia y Paz, Experiencia El Salvador". Panel-Forum: "Sociedad Civil y Desarrollo", patrocinado por la Asociación Latinoamericana de Organizaciones de Promocion,(ALOP) y FASTRAS.

2. Para un mayor desarrollo de esta temática consúllese mi trabajo: "La Nueva Economla Popular: una Utopla en Marcha".

3. También sobre esta temática se puede consultar mi trabajo antes citado.

4. Todo lo que a continuación exponemos ha sido tomado textualmente de nuesIro trabajo previamente citado. 